\title{
A CONFECÇÃO E USO DE UMA MINI ECOSFERA COMO PROPOSTA DE RECURSO DIDÁTICO NO ENSINO DE EDUCAÇÃO AMBIENTAL E SUSTENTABILIDADE
}

\author{
LA CONFECCIÓN Y USO DE UNA MINI ECOSFERA COMO PROPUESTA DE \\ RECURSO DIDÁCTICO EN LA ENSEÑANZA DE LA EDUCACIÓN AMBIENTAL Y \\ LA SOSTENIBILIDAD
}

\section{THE CONFECTION AND USE OF A MINI ECOSPHERE AS PROPOSAL OF DIDACTIC RESOURCE IN TEACHING OF ENVIRONMENTAL EDUCATION AND SUSTAINABILITY}

\author{
Levi Araujo Bezerra ${ }^{1}$; Luiz Carlos Alves de Souza ${ }^{2}$.
}

DOI: https://doi.org/10.31692/978-65-991061-4-9.75-91

\begin{abstract}
RESUMO
O ensino de ciências apresenta-se cada vez mais importante em nossa sociedade, principalmente pelo fato de vivenciarmos a ciência no nosso dia a dia. Dessa forma, a alfabetização científica torna-se essencial para instrumentalizar o discente para a linguagem científica. Entretanto, apesar dos avanços no campo da educação, o ensino de biologia tem sido realizado de forma com que o aluno seja um sujeito passivo, apenas recebendo o conteúdo, não participando de maneira ativa no processo de construção da sua aprendizagem. Desta forma, novas práticas para o ensino de ciências e biologia surgem com a demanda de tornar o aprendizado mais significativo e adequado a realidade do estudante. Diante disso, o uso de recursos didáticos como ferramenta pedagógica em disciplinas muitas vezes consideradas difíceis, pode ser uma excelente alternativa para facilitar o entendimento destas disciplinas, pois, o ensino, quando contextualizado, permite ao aluno interligar o conteúdo visto em sala com os assuntos do seu cotidiano, contribuindo assim na formação crítica e na construção do conhecimento, influenciando assim na participação e comprometimento. Como proposta para uma prática pedagógica diferenciada, este trabalho teve por objetivo descrever o processo de confecção de uma mini ecosfera, desenvolvida para auxiliar o professor em sala de aula quando o mesmo estiver trabalhando temas relacionados com ciências e biologia. Para a confecção do modelo foi utilizada como referência a Ecosfera original (Ecosferas $\left.{ }^{\circledR}\right)$, que surgiu a partir de pesquisas aeroespaciais desenvolvidas pela NASA. O presente modelo foi avaliado de forma positiva por alunos e o professor da disciplina de agroecologia do curso técnico em zootecnia do Instituto Federal de Educação Ciências e Tecnologia de Pernambuco - Campus Vitoria de santo Antão.
\end{abstract}

Palavras-Chave: Ecosfera, Educação Ambiental, Sustentabilidade, Recurso Didático.

\section{RESUMEN}

La enseñanza de las ciencias es cada vez más importante en nuestra sociedad, principalmente porque experimentamos la ciencia en nuestra vida diaria. Por lo tanto, la alfabetización científica se vuelve esencial para instrumentalizar al estudiante para el lenguaje científico. Sin embargo, a pesar de los avances en el campo de la educación, la enseñanza de la biología se ha llevado a cabo para que el alumno sea una asignatura pasiva, que solo recibe el contenido, no participa activamente en el proceso de construcción de su aprendizaje. Por lo tanto, surgen nuevas prácticas para la enseñanza de la ciencia y la biología con la demanda de hacer que el aprendizaje sea más significativo y apropiado para la realidad del estudiante. Dado esto, el uso de recursos didácticos como herramienta pedagógica en asignaturas que a menudo se consideran difíciles puede ser una excelente alternativa para facilitar la comprensión de estas asignaturas, ya que la enseñanza, cuando está contextualizada, permite al alumno vincular el contenido visto en el aula con las asignaturas. contribuyendo así a la formación

\footnotetext{
${ }^{1}$ Licenciando em Ciências Biológicas, Universidade Federal de Pernambuco, levitj1.lab@gmail.com

${ }^{2}$ Mestre em educação agrícola, professor do Instituto Federal de Pernambuco Campus Vitória de Santo Antão, nagusto.eaf@ hotmail.com
} 
crítica y la construcción del conocimiento, influyendo así en la participación y el compromiso. Como una propuesta para una práctica pedagógica diferenciada, este trabajo tuvo como objetivo describir el proceso de hacer una mini ecosfera, desarrollada para ayudar al maestro de aula cuando está trabajando en temas relacionados con la ciencia y la biología. Para hacer el modelo se utilizó como referencia la Ecosfera original (Ecospheres $\left.{ }^{\circledR}\right)$, que surgió de la investigación aeroespacial desarrollada por la NASA. El presente modelo fue evaluado positivamente por los estudiantes y el profesor de la disciplina de agroecología del curso técnico en zootecnia del Instituto Federal de Ciencias de la Educación y Tecnología de Pernambuco - Campus Vitoria de santo Antão.

Palabras Clave: Ecosfera, Educación ambiental, Sostenibilidad, Recurso didáctico.

\section{ABSTRACT}

Science teaching is becoming increasingly important in our society, mainly because we experience science in our daily lives. Thus, scientific literacy becomes essential to instrumentalize the student for scientific language. However, despite advances in the field of education, the teaching of biology has been carried out so that the student is a passive subject, only receiving the content, not actively participating in the process of building their learning. Thus, new practices for science and biology teaching arise with the demand to make learning more meaningful and appropriate to the student's reality. Given this, the use of teaching resources as a pedagogical tool in subjects that are often considered difficult may be an excellent alternative to facilitate the understanding of these subjects, since teaching, when contextualized, allows the student to link the content seen in the classroom with the subjects. thus contributing to the critical formation and construction of knowledge, thus influencing participation and commitment. As a proposal for a differentiated pedagogical practice, this work aimed to describe the process of making a mini ecosphere, developed to assist the classroom teacher when he is working on science and biology related topics. To make the model was used as reference the original Ecosphere (Ecospheres $\left.{ }^{\circledR}\right)$, which emerged from aerospace research developed by NASA. The present model was positively evaluated by students and teacher of the agroecology discipline of the technical course in zootechnics of the Federal Institute of Education Sciences and Technology of Pernambuco - Campus Vitoria de santo Antão.

Keywords: Ecosphere, Environmental education, Sustainability, didactic Resource.

\section{INTRODUÇÃO}

A ausência de responsabilidade ambiental da sociedade é consequência da desinformação, falta de participação e envolvimento da população com temas relacionados ao meio ambiente. E neste sentido, a educação ambiental representa um instrumento essencial para superar este problema. A relação entre meio ambiente e educação, assume um papel cada vez mais importante, demandando a necessidade de novos conhecimentos e métodos para o entendimento de processos e riscos ambientais que surgem em nossa realidade (PERETTI, 2012).

O ensino de educação ambiental e sustentabilidade tem um papel relevante para a compreensão dos ciclos biogeoquímicos que ocorrem em diferentes escalas em todo o mundo, pois, as informações adquiridas através de seus conteúdos vão desde o entendimento de conceitos básicos, até as mais complexas relações ecológicas desenvolvidas entre os organismos e o meio ambiente.

Mas, pela forma tradicional de como os conteúdos são ensinados, a compreensão, por parte do estudante, muitas vezes é dificultada, fragmentada e descontextualizada de sua 
realidade social sendo assim, a maneira como o ensino vem sendo abordado, pouco desperta o interesse de buscar novos conhecimentos (ZANELLA, 2013).

O reflexo do ensino tradicional é a fragmentação e a memorização dos conteúdos, o que acaba tornando o ensino e aprendizagem em sala pouco produtivo. O conhecimento científico, por exemplo, da forma como ele é ministrado nas escolas, termina por aumentar o desinteresse dos educandos que apenas memorizam de forma fragmentada. Nesse sentido, no que tange aos professores, o trabalho interdisciplinar pode auxiliar a superação desses currículos fragmentados e desarticulados com a realidade discente. Dessa forma, Fazenda (1994), afirma que a prática interdisciplinar pressupõe a possibilidade do "encontro", da "partilha", da cooperação e do diálogo entre os envolvidos na ação. Sendo assim o cotidiano escolar deverá mudar significativamente. ${ }^{3}$

Como consequência dessa concepção de educação tradicional, o estudante é visto como sujeito passivo, um mero ouvinte e o professor, muitas vezes, como o detentor do conhecimento. Sendo assim, a disciplina acaba sendo vista como um conjunto de conteúdo específicos de uma área e o objetivo do professor com sua disciplina acaba, muitas vezes, resumindo-se a ministrar o conteúdo proposto no livro didático, esquecendo-se como aponta Carvalho (2013), que o objetivo central da educação formal é a aprendizagem e do ensino, especificamente, é "ensinar a falar ciências", conduzir os estudantes da linguagem cotidiana para linguagem científica.

Para que os estudantes sejam alfabetizados cientificamente, as aulas devem estar organizadas de forma interativa e dinâmica, buscando compreender a concepção prévia dos discentes por meio da participação ao longo das aulas (CARVALHO, 2013). Portanto, cabe também ao professor quebrar o pensamento tradicionalista, fazendo com que o estudante se torne protagonista do processo de construção do seu conhecimento, partindo de uma situação real, em que o estudante encontre significado no conteúdo apresentado (CORDEIRO, 2017).

Diante do apresentado e bebendo da fonte de Carvalho e Gil-Perez (2011) dentre outros pesquisadores, compreende-se que o ambiente escolar independente de seu nível, deve

\footnotetext{
${ }^{3}$ Diante disso, e da própria organização dos sistemas escolares, que de modo implícito possuem como parâmetros para a construção dos novos currículos as provas de grande escala (Um forte exemplo é a Lei de 13.417/2007 que propôs uma nova reforma no Ensino Médio com o objetivo de tornar o currículo mais flexível, composto pela Base Nacional Comum Curricular (BNCC) e pelos seguintes itinerários formativos. Segundo seus idealizadores, tal proposta vem com o objetivo de melhorar os índices educacionais (Ideb) que não estavam tendo melhoras nos últimos anos. A própria organização da BNCC vem priorizando as disciplinas que são avaliadas nas grandes avaliações educacionais que são: português e matemática), os mecanismos utilizados para a aprendizagem acabam sendo memorísticos, tendo em vista que, muitas vezes os conteúdos acabam não sendo compreendidos pelos estudantes.
} 
ser visto também como espaço de pesquisa, capaz de produzir conhecimento. Desta forma, as concepções de ensino de ciências bem como das metodologias de ensino precisam ser revistas, o estudante precisa ser levado em consideração dentro desse processo.

Segundo Amorim (2013), os modelos didáticos, são facilitadores do processo de ensino, contribuem para a aprendizagem significava, pois permitem ao discente ter participação ativa em seu processo de ensino e aprendizagem. Os modelos complementam o conteúdo dos livros didáticos, que na maioria das vezes são encarados pelo estudante, como algo composto por termos a serem decorados, com imagens que não são compreendidas (ORLANDO, et al., 2009, p. 2).

Para Cavalcante e Silva (2008, p.01), os modelos didáticos permitem a experimentação e a prática, propiciam diferentes condições para a compreensão dos conceitos mais complexos, aqueles que exigem grande capacidade de abstração, estimulando o engajamento intelectual dos alunos com os objetos e fenômenos apresentados, contribuindo, também, para reflexões sobre o mundo em que vivem.

Diante dos problemas diários em sala de aula, o professor sente a necessidade de aprimorar suas aulas com métodos que venham a amenizar problemas como a dificuldade de perceber estruturas e processos, para Setúval e Bejarano (2009, p.04) “os modelos didáticos são instrumentos sugestivos e que podem ser eficazes na prática docente diante da abordagem de conteúdos que, muitas vezes, são de difícil compreensão pelos estudantes”.

Dentre as diversas estratégias a que o professor pode recorrer, os modelos didáticos podem constituir uma excelente alternativa que proporciona explorar múltiplas possibilidades de aprendizagem para os estudantes. Até mesmo para o próprio professor que, muitas vezes, demonstra insegurança ao ensinar alguns conteúdos de maior complexidade.

Segundo Carvalho e Gil-Pérez (2011) para modificar as concepções e metodologias no ensino, faz-se necessária uma profunda revisão da formação inicial e continuada dos professores, estendendo também ao avanço das pesquisas sobre aprendizagem das ciências e, em especial, as propostas de orientação construtivistas. Desta forma, este estudo tem por objetivo apresentar o processo de confecção de uma mini ecosfera e as contribuições deste recurso didático no ensino e aprendizagem de conteúdos como educação ambiental e sustentabilidade nas turmas de agroecologia do curso técnico subsequente em zootecnia do IFPE - Campus Vitória de Santo Antão.

\section{FUNDAMENTAÇÃO TEÓRICA}

Desde o início da humanidade, o ser humano sempre fez uso de objetos para facilitar a 
execução de suas atividades diárias. Pesquisas indicam que os primeiros objetos produzidos pelo homem eram simples, feitos manualmente. Acredita-se que eles eram utilizados como martelos, objetos de corte, caça e defesa. Todo esse processo de desenvolvimento foi impulsionado pela pressão natural e necessidade de sobrevivência no planeta. (FREITAS, 2007)

De acordo com Burg, Fronza e Silva (2013) no começo, os materiais eram usados da maneira como eram encontrados e com o decorrer do tempo, passaram a ser mais sofisticados. O ser humano passou a desenvolver novas formas de interagir entre si e com o meio, inicialmente com os desenhos de seu dia a dia, como figuras próprias e de animais pintados em cavernas, passando pela escrita cuneiforme, a escrita mais antiga que se tem conhecimento, até chegarmos ao primeiro alfabeto fonético, precursor do alfabeto utilizado atualmente. (PARELLADA, 2009).

Os primeiros grupos humanos a fixarem-se na terra, dominando a agricultura e domesticando animais, preocuparam-se com a transmissão do conhecimento aos mais jovens, tendo em vista prepará-los para a sobrevivência e defesa. Nesse período, além da observação e imitação por parte dos mais novos, a exposição oral era a ferramenta utilizada para transmitir o aprendizado e os costumes do grupo. (FREITAS, 2007; MORETTI, 2011)

A necessidade em desenvolver métodos de comunicação, demonstra uma preocupação em facilitar o processo de ensino aprendizagem, uma vez que era preciso garantir a atenção e estimular a atenção de seus descendentes. O lúdico é outro aspecto percebido nas técnicas utilizadas para transmitir o conhecimento, uma vez que as dramatizações proporcionam prazer aos aprendizes. (DAVIS, 2009)

Esses são alguns exemplos de como o ser humano, sempre lançou mão de desenvolver diferentes métodos para melhoram sua qualidade de vida, até mesmo na educação. Essa é, portanto, uma característica humana, buscar estratégias facilitadoras de seu processo de aprendizagem. (FREITAS, 2007)

Atualmente, a necessidade em desenvolver novos métodos de ensino e aprendizagem, surge pelas novas exigências deste sistema social. E como forma de responder a essas exigências, surgem os recursos didático - pedagógicos que permitem ao professor desenvolver um tipo de aula diferenciada, dinâmica e proveitosa. Não se sabe quando começaram a ser utilizados em aula, mas, esses recursos já são desenvolvidos há muito tempo, geração após geração, tendo alcançado bons resultados. (BRAGA, 2007, p. 4).

Esta ferramenta didática, quando corretamente utilizada, propícia o desenvolvimento espontâneo e criativo dos estudantes, permitindo também ao professor ampliar seus 
conhecimentos acerca das técnicas de ensino e o desenvolvimento de capacidades pessoais e profissionais para estimular nos estudantes a capacidade de expressão e argumentação, mostrando-lhes uma maneira mais prazerosa de relacionar-se com o conteúdo ensinado, levando-os à uma maior apropriação dos conteúdos trabalhados.

Segundo Santos, (2013) a partir do momento que se desenvolve uma relação entre o indivíduo com as atividades na sala de aula, cria-se um ambiente de socialização e troca de informações, revelando outro ponto importante dos recursos didáticos que desperta a curiosidade, a capacidade de observar, de questionar e uma melhor interação nas atividades. Estes recursos são instrumentos sugestivos e que podem ser eficazes na prática docente diante da abordagem de conteúdos que, muitas vezes, são de difícil compreensão. (SETÚVAL E BEJARANO, 2009, p. 04)

Muitos professores utilizam quase que unicamente o livro didático, pois é o recurso mais acessível, já que as escolas públicas recebem livros para utilização dos professores. Sendo um recurso acessível, muitas vezes por comodismo, a única opção utilizada pelo professor em suas aulas, deixando de incorporar outras ferramentas que poderiam auxiliar no ensino-aprendizagem. (NICOLA, PANIZ, 2017)

Para Cavalcante e Silva (2008), os recursos didáticos em que os alunos possam visualizar, são de grande importância, pois o professor consegue mostrar de forma explicita o que pretende trabalhar e o estudante, através da visualização, pode ter uma melhor fixação do conteúdo. As apresentações em PowerPoint, são um excelente exemplo, onde é possível associar texto, imagens e animações, demonstrando o que está sendo estudado. (NICOLA, PANIZ, 2017)

Ainda, segundo Nicola e Paniz, (2017) Independentemente do tipo de recurso, o seu uso, exige do professor planejamento e clareza de objetivos a serem alcançados, ou seja, o que se quer e quais conhecimentos podem ser construídos ou ampliados a partir destes recursos.

Para formar adultos cientes de suas responsabilidades ambientais com a natureza e que optem por um estilo de vida sustentável, a escola é o melhor ambiente para estimular uma consciência sustentável, pois os estudantes são mais suscetíveis a determinadas ponderações. "Pelo fato de encontrarem-se em uma fase de tomada de decisões, onde viver de forma sustentável é uma opção plausível”. (COSTA, 2018)

Segundo Amorim (2013), neste contexto, os modelos didáticos, são facilitadores do processo de ensino, contribuem para a aprendizagem significava, pois permitem ao discente ter participação ativa em seu processo de ensino e aprendizagem. Os modelos complementam o conteúdo dos livros didáticos, que na maioria das vezes são encarados pelo estudante, como 
algo composto por termos a serem decorados, com imagens que não são compreendidas (ORLANDO, et al., 2009, p. 2).

\section{METODOLOGIA}

O presente recurso, foi produzido por um discente do curso de Ciências Biológicas da UFPE-CAV, durante os meses de abril e junho de 2018, para ser exposto como recurso didático no ensino de educação ambiental, como requisito para obtenção de aprovação parcial na referida disciplina. Foi utilizado como recurso didático nas dependências do instituto Federal de Educação Ciências e Tecnologia de Pernambuco - Campus Vitoria de Santo Antão, na Disciplina de Agroecologia do curso técnico subsequente em zootecnia.

Para a confecção do modelo foi utilizada como referência a Ecosfera original $\left(\text { Ecosferas }{ }^{\circledR}\right)^{4}$, que surgiu de pesquisas aeroespaciais desenvolvidas pela NASA, que procuravam construir um sistema fechado no espaço onde os astronautas poderiam sobreviver durante longas viagens, em um ambiente autossuficiente, que fosse capaz de produzir recursos e manter o ar e a água limpos e reutilizáveis. Como resultado surgiram as Ecosferas produzidas pelo grupo internacional Ecospheres ${ }^{5}$.

A NASA cedeu esta tecnologia para que a sociedade pudesse entender o equilíbrio e funcionamento da natureza, a Ecosfera, é um ecossistema fechado e autossuficiente que pode ser usado como um excelente recurso de ensino e aprendizagem capaz de fornecer informações acerca da vida e de seu delicado equilíbrio em nosso planeta.

A Ecosfera, funciona como uma bateria biológica que armazena a energia luminosa transformada bioquimicamente, é um globo de vidro, com um ecossistema marinho, já o modelo que será apresntado a seguir, é a representação de um ecossistema contendo um grupo de organismos de ambiente dulcícola, sendo composto por um recipiente de acrílico lacrado, contendo água doce, basalto e quartzo triturados, substrato fértil, plantas aquáticas Echinodorus amazonicus, musgos Taxiphyllum barbieri, quatro camarões Neocaridina davidi e um casal de limpa vidro Parotocinclus maculicauda.

Figura 1: (A) Echinodorus amazonicus ${ }^{6}$; (B) Taxiphyllum Barbieri ${ }^{7}$; (C) Neocaridina davidi ${ }^{8}$ e (D) Parotocinclus maculicauda?.

\footnotetext{
${ }^{4}$ Objeto utilizado como modelo, (https://www.ecosferas.com/view_ecosferas/es/inicio.html. ).

${ }^{5}$ Endereço digital da empresa Ecospheres (https://eco-sphere.com/ ).

${ }^{6}$ Fonte: http://akvarium.dp.ua/wp-content/uploads/ngg featured/ehinodorus-blehera-400x533.jpeg

${ }^{7}$ Fonte: http://peixesdeaquario.com.br/plantas-2/musgo-de-java/

${ }^{8}$ Fonte: http://peixesdeaquario.com.br/wp-content/uploads/CAmar\%C3\%A3o-Red-Cherry-672x372.jpg

${ }^{9}$ Fonte: https://i.pinimg.com/736x/5f/d5/9a/5fd59a3db5126c07c35781e1485d4bb0--aquaria-tropical-fish.jpg
} 

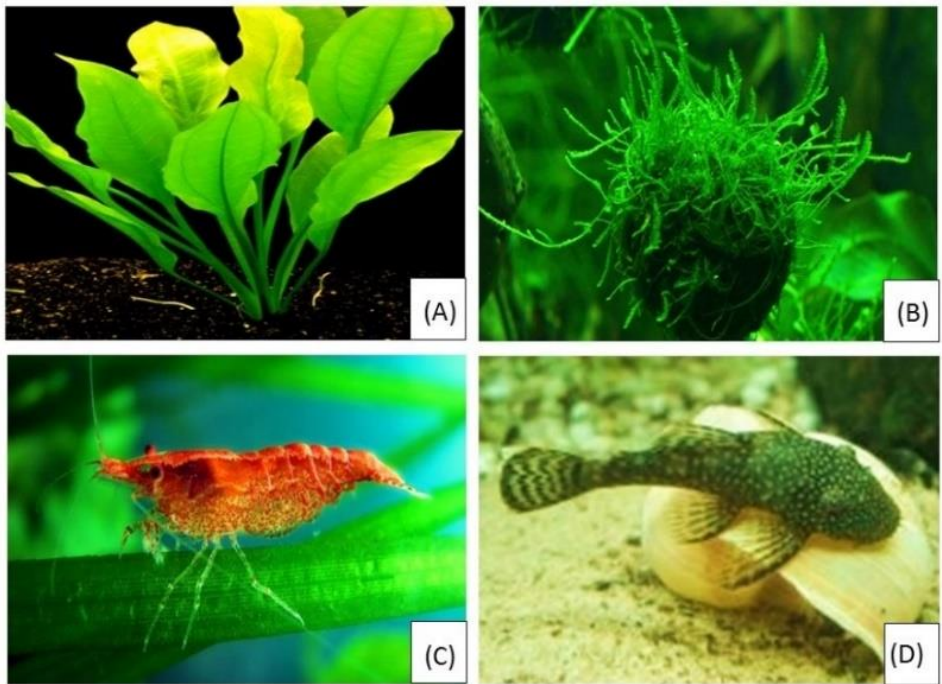

Antes de iniciar a confecção do modelo, foram produzidos dois protótipos, com outras variedades de plantas aquáticas e animais, para verificar quais seriam os organismos mais adequados para esse tipo de ambiente. Após montados e observados num período de três meses, optou-se pelo uso dos organismos citados acima, pois foram os mais adequados aos critérios como: organismos que não apresentam comportamento agressivo entre si, resistência a variação de parâmetros de $\mathrm{PH}$, oxigênio diluído na água, variação de temperatura, ciclo de vida de pelo menos dois anos e baixo custo.

Figura 2: (E) imagem de modelo de protótipo colado e em fase de secagem do silicone; (F) imagem de protótipo pronto com plantas já cultivadas e em desenvolvimento, $(\mathrm{G})$ imagem de protótipo 2, montado com plantas e animais em desenvolvimento.

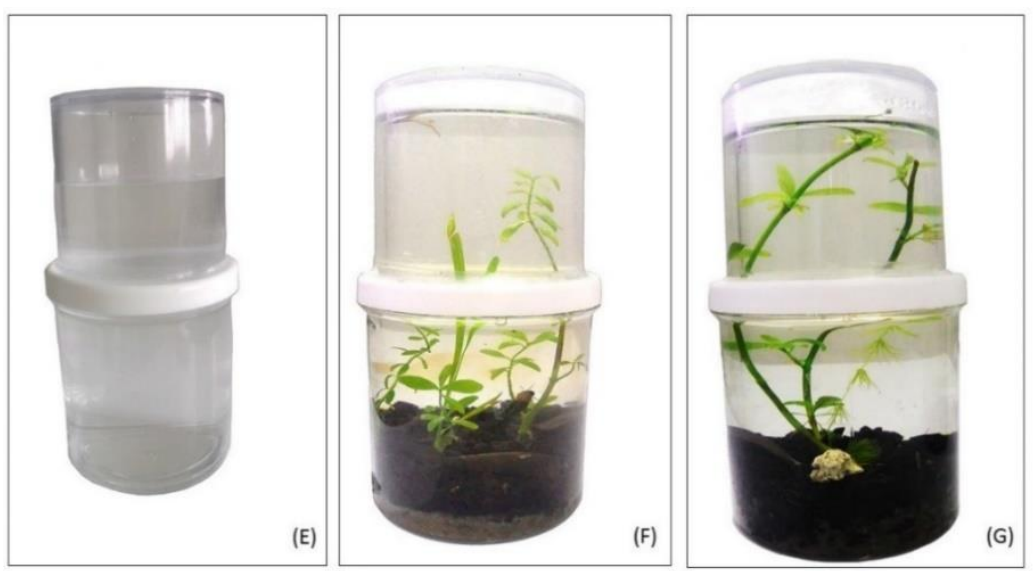

Fonte: Própria, 2019

Para a confecção do modelo definitivo, foram utilizados dois potes de acrílico cilíndricos, (600 ml e $2.000 \mathrm{ml})$ e silicone Sil Trade próprio para montagem de aquários, as tampas dos dois potes, foram cortadas para que ambas fossem coladas de forma perpendicular, servindo de apoio para fixar o pote menor sobre o maior.

Após o corte, as tampas foram coladas com o silicone sobre o pote maior, foi aguardado um período de dez dias para a secagem completa do silicone. Em seguida, para 
montagem do substrato, foi colocado duzentos gramas de basalto negro e cem gramas de quartzo triturado, sobre uma camada de dois centímetros de humos de minhoca, depois foram colocadas as plantas aquáticas, água tratada com os parâmetros adequados para os animais e plantas que farão parte do ecossistema e por fim, os camarões e os limpa vidro.

Para acelerar o processo de maturação do sistema, foi adicionado $100 \mathrm{ml}$ da água de um aquário já estabilizado com uma microbiota de algas e bactérias bem estabelecidas. Após serem colocados todos os itens, o pote menor foi colocado sobre o maior e fixado com fita isolante e silicone resistente a água.

Cada componente deste ecossistema desempenha um papel vital no equilíbrio do mesmo, as plantas aquáticas recebem a luz solar e iniciam a fotossíntese liberando oxigênio que será consumido pelos camarões e os limpa vidro que também serão nutridos com algas e bactérias que se desenvolvem a todo momento dentro da estrutura.

As bactérias nitrificantes, decompõem os dejetos dos animais, disponibilizando recursos para que as plantas aquáticas continuem seu desenvolvimento, os crustáceos, peixes e bactérias também produzem dióxido de carbono que é utilizado pelas algas e plantas aquáticas no processo de fotossíntese.

Todos os animais são consumidores. Os herbívoros, alimentam-se de plantas, são, portanto, consumidores primários. Os animais que se alimentam de herbívoros são consumidores secundários, os que se alimentam dos secundários são consumidores terciários e assim por diante; os decompositores, degradam a matéria orgânica presente em produtores e consumidores de todas as cadeias citadas, utilizam os produtos da decomposição como alimento e liberam no meio ambiente minerais e outras substâncias, que podem ser novamente utilizados pelos produtores.

Figura 3: (H) Modelo de mini ecosfera, montada e em desenvolvimento.

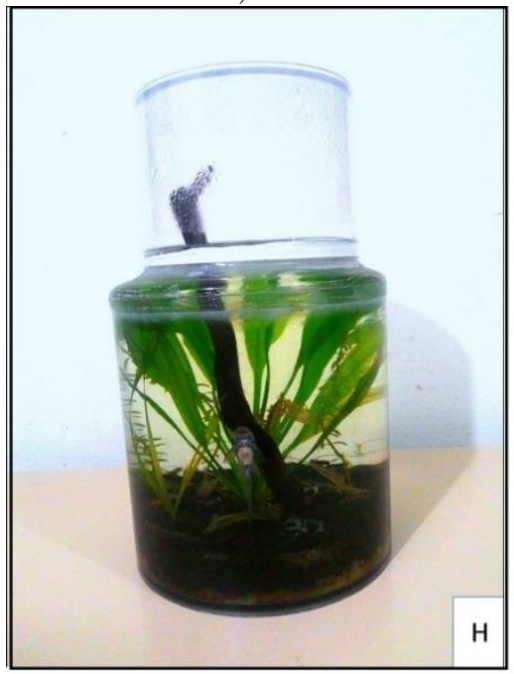

Fonte: Própria, 2019. 
Após a elaboração do recurso didático, foram selecionadas duas turmas do curso técnico em zootecnia do IFPE- Campus Vitoria de Santo Antão, para uma turma (turma A), foi planejada e ministrada, uma aula, fazendo uso da ecosfera como recurso didático e de apresentações em Power point, para a outra turma, (turma B) foi realizada a exposição oral e apresentações em Power point do mesmo conteúdo apresentado a turma A. Em seguida, foi elaborado um questionário com 6 questões acerca do conteúdo da aula. Na turma A, haviam 25 alunos e na turma B, 30 alunos.

Após o termino da aula, foi aplicado um mesmo questionário sobre meio ambiente e sustentabilidade para todos os alunos, e em seguida coletados, os resultados foram analisados como descrito a seguir.

\section{RESULTADOS E DISCUSSÃO}

Os alunos da turma A, durante a apresentação deste modelo, tiveram a oportunidade de montar um exemplar e relembrar os conteúdos previamente estudados na disciplina de agroecologia como por exemplo, as relações ecológicas e sustentabilidade. A partir dos dados obtidos, as discursões e observações foram realizadas e para facilitar o entendimento dos dados, foram construídos gráficos.

$\mathrm{Na}$ questão número 1 , foi solicitado que os alunos conceituassem o que seria sustentabilidade, observou-se que as duas turmas, Turma A e turma B, apresentaram o mesmo índice de acerto (50\% de acertos em ambas as turmas) a similaridade no índice de erros e acertos, pode ser justificada pelo fato de os alunos responderem essa questão tendo como base o material exposto em Power point. Segundo Nicola e Paniz (2017), a apresentação em PowerPoint, é um excelente recurso, onde é possível associar texto com as imagens e animações, demonstrando claramente o que está sendo estudado.

$\mathrm{Na}$ questão número 2, os alunos tinham cinco figuras com diferentes significados, e deveriam relacionar uma das figuras com o tema sustentabilidade, dessas figuras, apenas uma representava o foco de abordagem da sustentabilidade, para assinalar essa alternativa, era necessário que o aluno conseguisse associar a figura adequada com a palavra, nesta questão, a Turma A apresentou $90 \%$ de acertos enquanto que a turma B apresentou $60 \%$ de acertos. 
Gráfico 1. Índice de acertos na associação de imagens ao conceito.

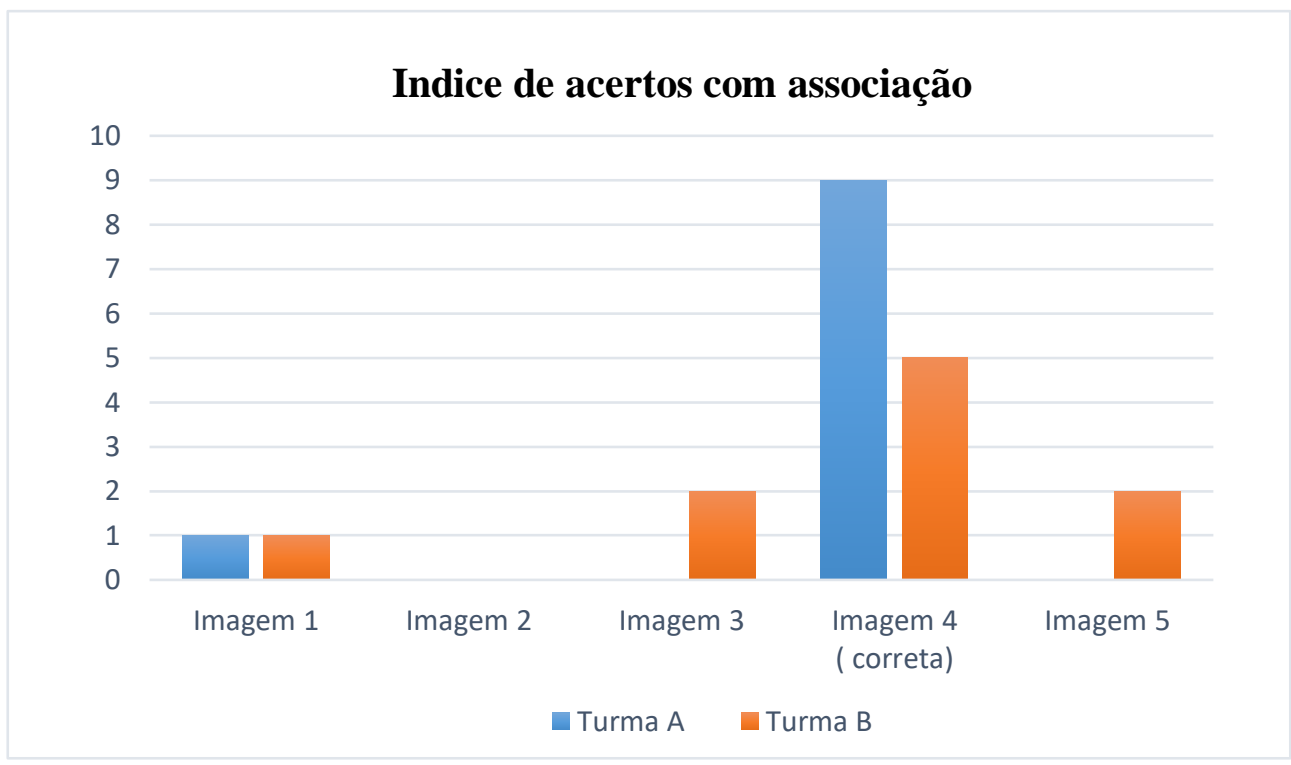

Fonte: Própria, 2019.

O diferencial de acertos entre as turmas, pode ser atribuído ao fato de os alunos da turma A, além de observarem as imagens apresentadas puderam interagir com o recurso didático e relacionar o conteúdo estudado com o funcionamento do ecossistema. Segundo Amorim (2013), os modelos didáticos, são facilitadores do processo de ensino contribuindo para a aprendizagem significava, pois permitem ao discente ter participação ativa em seu aprendizado.

$\mathrm{Na}$ questão número 3 , os alunos deveriam conceituar a palavra agroecologia, ao analisar as respostas apresentadas pela turma A, 45\% dos alunos apresentaram o conceito da palavra agroecologia associando com o funcionamento da ecosfera, como exemplo, é possível citar a resposta do aluno A1 $1^{10}$, que diz: “ A agroecologia é uma parte da ecologia que estuda a agricultura sustentável, tentando manter o melhor equilíbrio possível na produção e na preservação do solo e do ambiente, tentando chegar no equilíbrio similar ao que a gente pode ver na ecosfera, que os animais comem as plantas mas só o que precisam, fazendo com que a planta consiga se renovar e tudo ficar em equilíbrio". No geral, a turma A apresentou um índice de $70 \%$ de acertos definindo a agroecologia, enquanto que a turma B apresentou 55\% de acertos.

Em seguida, na questão número 4, era necessário associar a agroecologia com algumas imagens, indicando a imagem que melhor trouxesse elementos importantes para associação

\footnotetext{
${ }^{10}$ Cada questionário respondido foi nomeado com a letra referente a turma (A ou B) e enumerado de acordo com a ordem de analise, como exemplo: A11, A14 e B2.
} 
com os três pontos de foco e abordagem da agroecologia. A turma A, apresentou $90 \%$ de acertos enquanto que a Turma B apresentou $60 \%$.

$\mathrm{Na}$ questão número 5, foi solicitado que os alunos descrevessem um ecossistema e apontassem como o extrativismo descontrolado poderia desequilibrar ou destruir o ecossistema. Nesta questão, 30\% dos alunos da turma A, descreveram ecossistemas similares ou iguais ao da ecosfera, e apontaram fatores como a extração exacerbada de nutrientes do solo, a destruição de produtores primários e redução da variedade de indivíduos. No geral $80 \%$ dos alunos da turma A, responderam esta questão de maneira satisfatória. Enquanto que $45 \%$ dos alunos da turma B, responderam satisfatoriamente esta questão.

$\mathrm{O}$ fato de parte dos alunos da turma A descreverem ecossistemas similares ou iguais a ecosfera e boa parte da turma conseguir responder à questão 5, pode estar associado a circunstância de terem a oportunidade de montar uma ecosfera e entender a função de cada componente presente no sistema. No estudo realizado por Cavalcante (2008), professores foram questionados a respeito de qual a melhor maneira de ensinar, eles enfatizaram a necessidade de permitir aos alunos ter oportunidades onde possam relacionar teoria e a prática, ou seja, para que ambos não se tornem independentes e sim que haja uma complementação para o um melhor entendimento.

No item 6, os alunos foram questionados a respeito de como suas ações como futuros profissionais poderiam interferir no equilíbrio do meio ambiente. Os alunos de ambas as turmas, apontaram a importância de observar o ambiente, planejar as ações que serão desenvolvidas para evitar possíveis prejuízos ambientais, o respeito ao meio ambiente e a visão de preservar para os que virão a seguir. Mas comparando as respostas das turmas, é possível identificar maior investimento por parte dos alunos da turma $\mathrm{A}$, em justificar a importância de seu papel como futuro profissional, o aluno A 14, afirmou que " é preciso ter muito respeito pela natureza porque, quando eu for técnico em zootecnia e precisar trabalhar com animais como abelhas, vou precisar saber a importância desses animais para o meio ambiente e para a manutenção da natureza tendo que maneja-las com muito cuidado para não sobrecarregar o ambiente e respeitar os animais".

A constatação acima, corrobora com as afirmações de Nery et al (2017), o uso de modelos didáticos para o ensino da educação ambiental deve ser considerado devido sua relevância, uma vez que, não somente uma atividade mecânica, mas que possibilita ao aluno estabelecer interações que promovam um maior rendimento e sobretudo, quando se dá o estimulo participativo de forma a construir novas discussões e a formulação de novas hipóteses sobre o tema abordado. 
A questão número 7, apresentava uma escala de satisfação do tipo likert, solicitando a opinião dos alunos quanto a dificuldade em compreender o conteúdo apresentado. O gráfico abaixo apresenta em porcentagem o grau de dificuldade apontado por ambas as turmas, onde 0 corresponde a nenhuma dificuldade e 10, muita dificuldade em compreender o conteúdo, ficando claro uma maior dificuldade de entendimento por parte dos alunos da turma B.

Gráfico 2. Indicação de grau de dificuldade apontado pelos alunos de ambas as turmas.

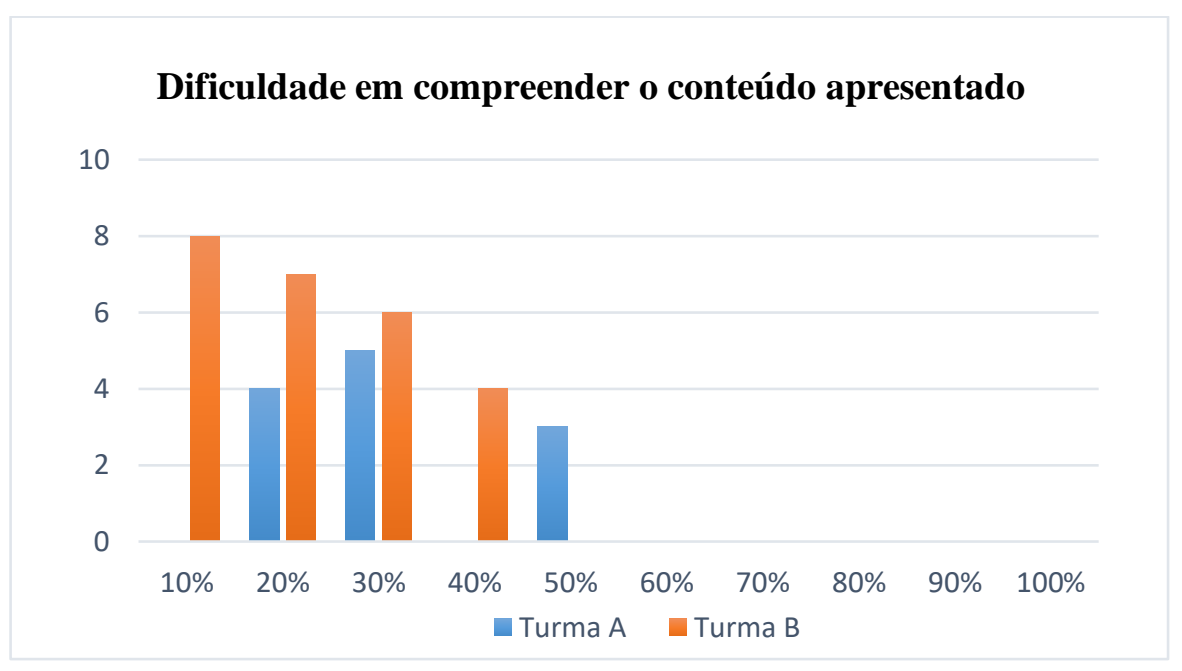

Fonte: Própria, 2019.

Por fim, na questão 8, os alunos da turma A responderam a seguinte indagação: "Em sua opinião, o uso da ecosfera como recurso didático, contribuiu para o entendimento dos conteúdos ensinados? Justifique". Enquanto que os alunos da turma B, foram incentivados a apontar possíveis sugestões para melhorar a metodologia utilizada com a turma. Como resposta para a questão $8,100 \%$ dos alunos da turma $\mathrm{A}$, afirmaram que a ecosfera contribuiu positivamente no seu processo de aprendizado, o aluno A10 afirmou que " a ecosfera é muito legal, porque funciona como um planeta terra em miniatura e dá para ver na pratica o que a gente acabou de ver sobre sustentabilidade", o aluno A13, relatou que " a ecosfera me ajudou a identificar como um organismo é dependente do outro, do mesmo jeito que nós dependemos das florestas e dos mares".

O aluno A16 afirmou que "me ajudou a entender o assunto apresentado e me incentivou a pensar no meu papel como indivíduo que faz parte de um grande ecossistema, que é o planeta terra". Os relatos acima permitem afirmar que, os recursos didáticos auxiliam a aproximação dos alunos com a contextualização da sua realidade e dos fenômenos naturais que ocorrem ao seu entorno, como afirma Silva e Bertazzo (2013), "ao utilizá-lo como proposta didática e pedagógica é possível não só tornar as aulas mais estimulantes e criativas, como também contextualizar o processo de ensino e aprendizagem. " 
Como resposta para a questão 8 , a turma $\mathrm{B}$, fez várias sugestões de melhoras para tornar as aulas mais interessantes, as recomendações com maior frequência foram, o uso de maquetes, aulas práticas para visualização dos fenômenos comentados em aula e exibição de vídeos e documentários.

É importante ressaltar o entusiasmo dos alunos da turma A, ao saberem que sairiam da rotina cotidiana de apenas assistir apresentações de slides, para uma atividade pratica e dinâmica. Com isso, notou-se o engajamento de todos os alunos em participar da atividade proposta de montar a ecosfera. Segundo Oliveira (2006), é por meio do processo de aprendizagem e do pensar sobre a realidade, que se rompe com as enlaças do ensino tradicional, da extensa e exaustiva descrição e memorização de conceitos.

\section{CONCLUSÕES}

A construção do modelo aqui apresentado possibilitou o aprimoramento e desenvolvimento de novas habilidades, mostrou-se um facilitador no ensino de novos saberes, de forma eficaz, permitindo observar os conteúdos de maneira dinâmica.

Relatos como os demonstrados neste estudo evidenciam que recursos didáticos possuem uma grande importância para a construção do conhecimento dos alunos, auxiliando na compreensão e complementando o conteúdo apresentado nos livros e trazendo a dinâmica das relações ecológicas e do meio ambiente, de uma formar que as figuras planas e, muitas vezes, descoloridas dos livros não podem trazer.

É importante destacar a necessidade do desenvolvimento de novos métodos e recursos educacionais, capazes de estimular o interesse do aluno em participar ativamente em seu processo de ensino e aprendizagem.

\section{REFERÊNCIAS}

AMORIM, A.S. A influência do uso de jogos e modelos didáticos no ensino de biologia para alunos de ensino médio. 2013. 49f. Monografia (Licenciatura em Ciências Biológicas) - Universidade Aberta do Brasil, Centro de Ciências e Saúde, Universidade Estadual do Ceará, Ceará, 2013. Disponível em: http://www.uece.br/sate/index.php/downloads/doc_download/2146-biobeberibeamorim>. Acesso em: 29 jul. 2019.

BURG, Silvana Montibeller; FRONZA, Silvio Luiz; SILVA, Thiago Rodrigo da. História da Educação: Caderno de estudos. Indaial: UNIASSELVI, 2013.

BRAGA, Andréa Jovane. Usos dos jogos didáticos em sala de aula. 2007. 
CARVAlHO, Anna Maria Pessoa. O ensino de ciências e a proposição de sequências de ensino investigativas. Em: CARVALHO, Anna Maria Pessoa. (Org.) Ensino de Ciências por investigação: condições para implementação em sala de aula. São Paulo: Cengage Learning, 2017.

CARVAlHO, Anna Maria Pessoa; GIL- PÉREZ, Daniel. Formação de professores de Ciências: tendências e inovações. São Paulo: Cortez, 10 ed, 2011.

CAVALCANTE, Dannuza; SILVA, Aparecida. MODELOS DIDATICOS E PROFESSORES: CONCEPÇÕES DE ENSINO-APRENDIZAGEM E EXPERIMENTAÇÕES. In: XIV Encontro Nacional de Ensino de Química, Curitiba, UFPR, jul de 2008. Disponível $\quad$ em: http://www.quimica.ufpr.br/eduquim/eneq2008/resumos/R0519-1.pdf> Acesso em 03 jul, 2019.

CORDEIRO, K. F. S.; SANTOS, L. R. F.; W. P. SANTOS. A utilização do júri simulado como metodologia alternativa de ensino nas séries finais do ensino fundamental na escola estadual pio XII - Irati-PR. In: XII Congresso Nacional de Educação, Curitiba. 2017. Disponível em: < http://educere.bruc.com.br/arquivo/pdf2017/24092_12021.pdf> Acesso em 01 jul, 2018.

COSTA, E.B: Visita Técnica Como Estratégia de Construção da Cidadania Ambiental com Alunos de Escola Pública em Teresina-PI. Trabalho de Conclusão de Curso (Graduação em Ciências Biológicas) - Instituto Federal de Ciências, Educação e Tecnologia do Piauí. Teresina-PI, p. 24. 2018.

DAVIS, H, A.; PAVAM, C.A. Coleção Enciclopédia Ilustrada de História, São Paulo, Brasil, Duetto Editorial, 2009.

MATOS, Cláudia; OLIVEIRA, Carlos Romero; SANTOS, Maria Patrícia; FERRAZ, Célia. Utilização de Modelos Didáticos no Ensino de Entomologia. Revista de Biologia e Ciências da Terra. Vol. 09, $\mathrm{n}^{\mathrm{o}}$ 01. Paraíba, 2009. Disponível em: < http://joaootavio.com.br/bioterra/workspace/uploads/artigos/3matos-51816c32b2719.pdf > Acesso em 01 Jul 2019.

FREITAS, Olga. Equipamentos e materiais didáticos. Brasília: Universidade Federal de Brasília, 2007. 132 p. Disponível em: http://portal.mec.gov.br/seb/arquivos/pdf/profunc/equip_mat_dit.pdf $>$ acesso em 01 Ago. 2019.

MORETTI, Vanessa Dias; ASBAHR, Flávia da Silva Ferreira; RIGON, Algacir José. O humano no homem: os pressupostos teórico-metodológicos da teoria histórico-cultural. Psicol. Soc., Florianópolis , v. 23, n. 3, p. 477-485, Dez. 2011 . Disponível em: < http://www.scielo.br/scielo.php?script=sci_arttext\&pid=S0102-71822011000300005 >.

Acesso em 09 Ago. 2019.

NERY, Gleydson, Kleyton Moura; NERY, Janiele, França; FERREIRA, Larissa, Macena.

Construção de modelos didáticos como ferramenta para o ensino de ciências. In: II Congresso Nacional de Pesquisa e Ensino em Ciências, Campina Grande, PB, junho de 2017. Disponívelem:<http://www.editorarealize.com.br/revistas/conapesc/trabalhos/TRABALHO_E V058_MD1_SA93_ID41_17052016220135.pdf> acesso em 01 jul 2019. 
NICOLA, Jéssica Anese; PANIZ, Catiane Mazocco. A importância da utilização de diferentes recursos didáticos no Ensino de Ciências e Biologia. InFor, [S.1.], v. 2, n. 1, p. 355-381, mai 2017. Disponível em: <https://ojs.ead.unesp.br/index.php/nead/article/view/InFor2120167>. Acesso em: 10 ago. 2019.

OLIVEIRA, M. M. A geografia escolar: reflexões sobre o processo didático-pedagógico do ensino. Revista Discente Expressões Geográficas, n. 2, p. 10-24. Florianópolis, 2006. Disponível em: < http://www.geograficas.cfh.ufsc.br/arquivo/ed02/artigo01.pdf >. Acesso em: 10 jun. 2019.

ORLANDO, T.C. et al. Planejamento, montagem e aplicação de modelos didáticos para abordagem de biologia celular e molecular no ensino médio por graduandos de ciências biológicas. Revista brasileira de ensino de bioquímica e biologia molecular, v.1, n.1, p.117, 2009. Disponível em: < http://bioquimica.org.br/revista/ojs/index.php/REB/article/view/33/29 >. Acesso em: 29 jul. 2019.

PARELLADA, Claudia Inês. ARTE RUPESTRE NO PARANÁ. Revista Científica/FAP, [S.1.], jun. 2009. ISSN 1980-5071. Disponível em: $<$ http://periodicos.unespar.edu.br/index.php/revistacientifica/article/view/1592>. Acesso em: 09 Ago. 2019.

PERETTI, Vanessa Aline. "Educação Ambiental na escola pública: o caso da EEEF José Ferreira Ramos-Gaurama/RS." Revista Eletrônica em Gestão, Educação e Tecnologia Ambiental. Rio Grande do Sul. Vol. 05, nº 05, p, 841 - 849, 2012. Disponível em: < https://periodicos.ufsm.br/reget/article/viewFile/4246/2814> acesso em: 09 ago, 2019

SANTOS, Ovídia Kaliandra Costa; Belmino; José Franscidavid Barbosa. RECURSOS DIDÁTICOS: UMA MELHORIA NA QUALIDADE DA APRENDIZAGEM. In: Fórum Internacional de Pedagogia, 5., 2013, Campina Grande. Anais... [...]. Campina Grande.Realize. 2013. Disponível em: < http://editorarealize.com.br/revistas/fiped/trabalhos/Trabalho_Comunicacao_oral_idinscrito__ fde094c18ce8ce27adf61aedf31dd2d6.pdf> acesso em 10 Ago, 2019.

SETUVAL, Francisco; BEJARANO, Nelson. Os modelos didáticos com conteúdos de genética e a sua importância na formação inicial de professores para o ensino de ciências e biologia. Bahia, 2008. Disponível em: http://posgrad.fae.ufmg.br/posgrad/viienpec/pdfs/1751.pdf>. Acesso em 12 de Jan de 2019.

SILVA, Laydiane Cristina da; BERTAZZO, Claudio Jose. O LÚDICO, A GEOGRAFIA E A MEDIAÇÃO DIDÁTICA. Revista Geoaraguaia, [S.1.], dec. 2013. ISSN 2236-9716. Disponível em: <http://periodicoscientificos.ufmt.br/ojs/index.php/geo/article/view/4868/3278>. Acesso em: 03 ago. 2019

THIESEN, Juares da Silva. A interdisciplinaridade como um movimento articulador no processo ensino-aprendizagem. Rev. Bras. Educ. Rio de Janeiro, v. 13, n. 39, p. 545-554, 2008. Disponível em: < <http://www.scielo.br/scielo.php?script=sci_arttext\&pid=S141324782008000300010\&lng=en\&nrm=iso >. Acesso em 02 ago. 2019. 
ZANELLA, Camila. As dificuldades que os professores enfrentam em sala de aula nos anos iniciais da docência. In: XI Congresso Nacional de Educação, Curitiba, PUCPR, setembro de 2013. Disponível em:

http://educere.bruc.com.br/arquivo/pdf2013/9875_6234.pdf > Acesso em 01 jul, 2019. 